\title{
Study of Material Flow and Mechanical Properties of Friction Stir Welded AA2024 with AA7075 Dissimilar Alloys using Top-Half-Threaded Pin Tool
}

\author{
Pragya Nandan Banjare*, Satya Kumar Dewangan and Manoranjan Kumar Manoj \\ Department of Metallurgical and Materials Engineering, Raipur, Chhattisgarh, India
}

('Corresponding author's e-mail: pnbanjare.phd2015.meta@nitrr.ac.in)

Received: 27 January 2021, Revised: 28 May 2021, Accepted: 29 June 2021

\begin{abstract}
This research work was aimed at evaluating the material flow behavior and mechanical properties of dissimilar aluminum alloys (2024 and 7075) joints prepared by friction stir welding using a tool with tophalf-threaded pin. Macro and microstructural study for material flow investigation was carried out. Whereas mechanical properties of welded joints are examined using tensile and micro-Vicker's hardness tests. Zeiss EVO 18 SEM was used for the fractographic study. Average grain sizes were determined at various weld regions. The effect of grain size with the hardness and strength has been discussed. The results demonstrate that the thread's location on the pin significantly affects the flow of the material. The area where the material has been severely plasticized and moved was located at the weld root. Hence welding root defects like void, pinhole, insufficient filling, etc. are avoided. The tensile strength of friction stir welded joint was $312.7 \mathrm{MPa}$, equivalent to the joint efficiency of $66.5 \%$.
\end{abstract}

Keywords: Welding, Microstructure, Defects, Friction stir welding, SEM

\section{Introduction}

One of the most challenging problems is to decrease the mass of an automobile or aircraft without compromising its safety performance [1-3]. Essential parts of an automobile are body, chassis, engine, exhaust system, transmission system, etc. are usually made of steel. However, aluminum alloys have clear advantages over steel, such as 3-fold lesser density, prominent recyclability, better corrosion resistance, etc. [4-6]. Weldability is a key factor for selecting material in automobile industries but aluminum alloy has very poor weldability hence not commonly used in the this industry [7-13]. These alloys will replace steel from most of the automotive part as the research on welding of these are progressing. Friction stir welding (FSW) is a solid-state welding method for the welding of aluminum alloys that was developed in $1991[14,15]$. The joint is produced by the use of frictional heat, severe plastic deformation, and material inter-mixing [16-21]. The process starts with a rotating tool that plunged into heavily clamped workpiece plates. When tool is fully plunged then it is allowed to move in a transverse direction to complete the weld. Tool rotational speed, traverse speed, and shoulder plunge depth are the most dominant process parameters [22]. A schematic diagram of weld configuration is shown in Figure 1. The tool is made of a cylindrical rod having tool pin tip which is slightly shorter than workpiece thickness. Tool shoulder generally 3 to 4 times in diameters than workpiece thickness. Friction between the rotating tool and clamped stationary workpiece generates frictional heat. Due to this heat, workpiece material is plasticized and mechanically intermixing of workpiece material takes place, it is similar to mixing and joining clay, or dough $[23,24]$. This modern joining technique is favorable for making aluminum welds because it avoids the solidification weld defects like contamination, blowholes, porosity, and solidification cracking [25-27]. The most commonly used material for aerospace and structural purpose are AA 2024 and AA 7075 where welding is a crucial aspect of manufacturing [12,28-31]. In the present study, a tool with a top half threaded pin is fabricated, intending to inhibit the defect thus improving the joint strength. The study is focused on the study of material flow and mechanical properties of friction stir welded AA2024 with AA7075 dissimilar alloys using the fabricated tool. 


\section{Materials and methods}

Selected workpiece materials and tool material in the present work are $6 \mathrm{~mm}$ thick AA 2024 T351, AA 7075 T651, and H-13 tool steel respectively. AA 2024 has been used on the advancing side and AA 7075 has been used on the retreating side. Tensile strength of the as-received AA 2024 and AA 7075 are 470.32 MPa and 566.21 MPa, respectively. Chemical and mechanical properties of workpiece material is given in Table 1. The selected welding speed and rotational speed are $40 \mathrm{~mm} / \mathrm{min}$ and 1,200 RPM respectively. The tool used in the experiments has top-half threaded pin (tool pin has a cylindrical shape having M6 size threads only at top half of tool pin) shown in Figure 2. Tool pin length is $5.8 \mathrm{~mm}$, pin diameter is $5.5 \mathrm{~mm}$ and shoulder diameter is $18 \mathrm{~mm}$. The tilt angle for the experiment is $2^{\circ}$ and dwell time is $20 \mathrm{~s} .100 \times 50 \times 6 \mathrm{~mm}^{3}$ workpiece plates are fastened in a fixture. Afterward rotating top halfthreaded tool is plunged into the workpiece plates, and after dwell period is over, the tool is traverse to complete the welding. After the welding tool is simply retracted from the welded plate.

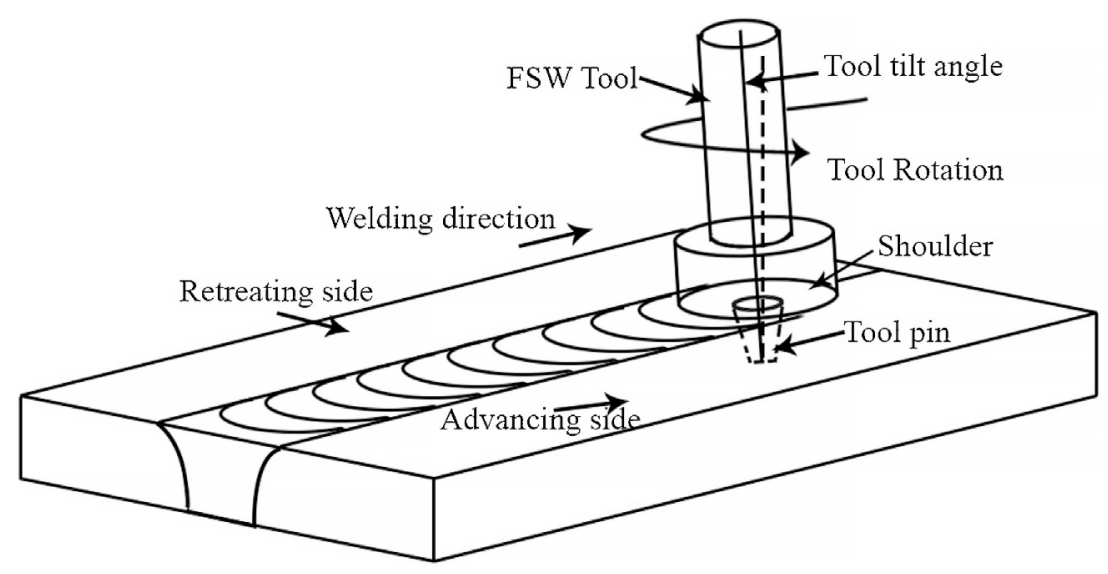

Figure 1 Schematic illustration of the friction-stir welding process [32].

Two tensile samples and 1 cross-section sample for microstructure and hardness tests are prepared from welded sample. The sample cutting scheme is shown in Figure 3. The polished cross-section samples are then etched using Keller's reagent $(2 \mathrm{~mL} \mathrm{HF}, 3 \mathrm{~mL} \mathrm{HCl}, 5 \mathrm{~mL}$ nitric acid, and $190 \mathrm{~mL}$ distilled water) and examined under macroscope, microscope and micro-hardness tester. Microhardness profiling of weld cross-section is done at $1 \mathrm{Kgf}$ load for $10 \mathrm{~s}$ and readings taken at $1 \mathrm{~mm}$ interval. The tensile specimens are prepared using CNC wire-cut EDM machine. The tensile tests are conducted at the ambient temperature corresponding to the ASTM-E8 standard. Instron 5980 universal testing machine is used for the tests with a constant crosshead speed of $1 \mathrm{~mm} / \mathrm{min}$.

Table 1 Chemical compositions and mechanical properties of workpiece material.

\begin{tabular}{lllllllllll}
\hline \multirow{2}{*}{ Alloy } & \multicolumn{9}{c}{ Chemical composition } & \multicolumn{3}{c}{ Mechanical properties } \\
\cline { 2 - 11 } & Al & Cu & Zn & Mg & Mn & Cr & Si & Fe & UTS (MPa) & Hardness (Hv) \\
\hline AA 2024 & 92.72 & 4.60 & 0.09 & 1.51 & 0.60 & - & 0.21 & 0.21 & 470.32 & 138 \\
AA 7075 & 89.56 & 1.12 & 5.58 & 2.04 & - & 0.33 & 0.40 & 0.20 & 566.21 & 160 \\
\hline
\end{tabular}




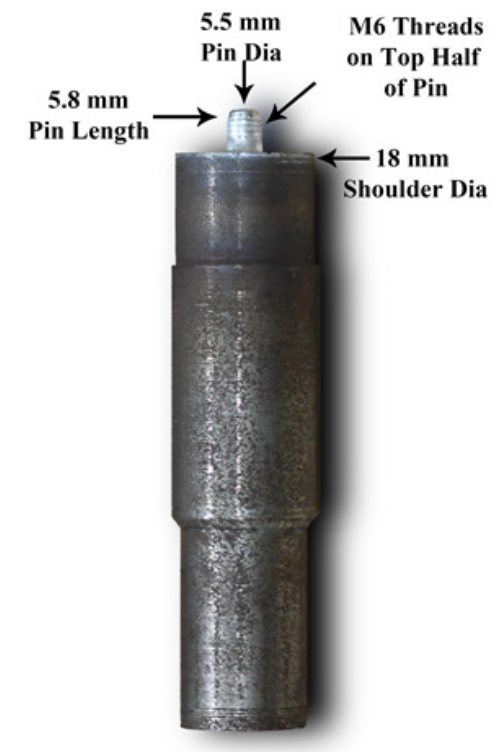

Figure 2 FSW tool with top half threaded pin.

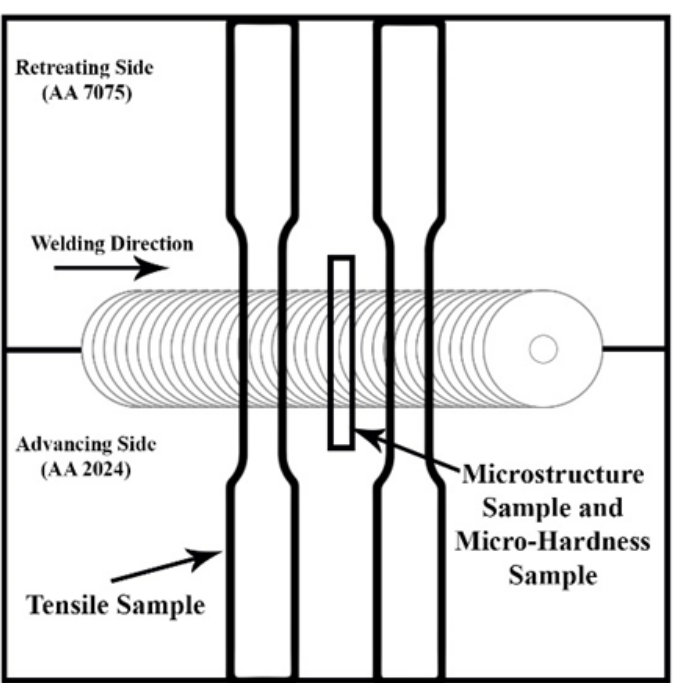

Figure 3 Sample cutting scheme.

\section{Results and discussion}

\section{Macro and microstructures}

The macro and microstructural analysis of the polished cross-section sample is done using Leica stereo macroscope and Zeiss optical microscopy respectively. Weld macrograph and micrographs are shown in Figures 4(a) to 4(c) respectively. Dark and light etched circles in stirred material is visible in Figure 4(a) which is called onion ring structure. No defects were found on welded samples. The rotating tool gives frictional heat to the base material by the effect of this heat, material get soften and stirred due to rotational movement of the tool, furthermore the grain at Thermo-Mechanical Affected Zone (TMAZ) area get deformed. These deformed elongated grains at TMAZ are visible in Figure 4(b) with grain size of 13.85 micrometers at TMAZ region. However, there is gradual variation in grain sizes according to the material deformation and material flow. The plasticized material flowing first downwards due to the thread direction then outward and upward which is very much concentrated near the weld root. therefore, it prevents any root defect such as void, pinhole and insufficient flow [33-35]. A very sharp change in grain size is observed between TMAZ and NZ in an optical micrograph which may act as a weak bonding 
area. Severe plastic deformation at the high temperature promotes dynamic recrystallization, hence very fine grains at the NZ which are visible at high magnification. very fine equiaxed grains with 4.86 micrometers grain size at the weld nugget zone (NZ) can be seen in Figure 4(c). Material at nugget zone rotates with the tool pin at very high rotational speed which results in severe plastic deformation of plasticized material at NZ. However, the material at TMAZ rotates at much slower speed as the material does not get very soft. It moves due to the sticking friction between material at NZ and material at TMAZ. This causes the formation of very fine grains at NZ and elongated coarse grains at TMAZ. The high material flow region (onion ring) and low material flow (welding region below shoulder) region may have poor bonding due to the difference in material flow. This region may have high-stress concentration and weak bonding which can develop the crack initiation site.

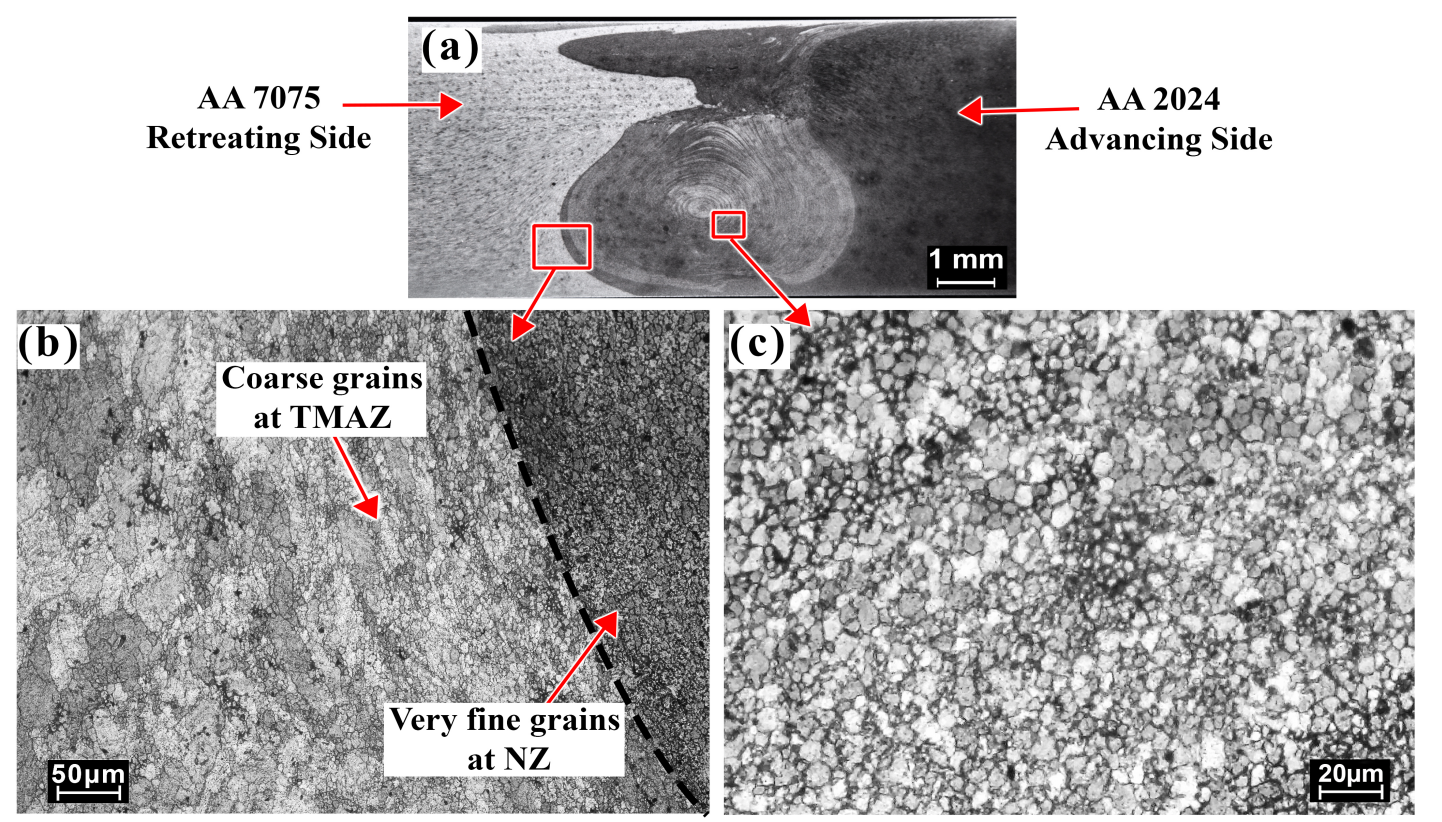

Figure 2 (a) Weld macrograph (b) weld micrograph at NZ and TMAZ interface (c) weld micrograph at center area of NZ.

\section{Material flow and structure formation}

Material flow due to the top half threaded pin tool is illustrated in Figures $\mathbf{5}$ and 6. The top-half threaded pin keeps the softened material concentrated at the weld root whereas there may be very less vertical flow at the shoulder region of the weld. Therefore, heavy flow lines at weld center to weld root and a straight flow close to the tool shoulder region can be observed. Figure 5 explains the material flow direction due to the thread. Due to the high rotational speed tool travers plasticized material moves towards the weld seam. Threads present at tool pin pushes the material downwards, then it moves outwards and finally upwards. The thread-less part of pin helps to intermix the material horizontally but there is very little vertical material flow due to the absence of threads. The creation of onion rings in various steps are illustrated in Figure 6. In step 1 the plasticized material moves downwards (Figure 6(a)) now in step 2 the material has no further place to flow so it starts to flow outwards (Figure 6(b)). In step 3 the plasticized material reached to the more viscous and solid region it moves in an upward direction and starts to form onion ring structure (Figure 6(c)). In step 4 the material near the shoulder come closer, fill the blank space, and completes the joint (Figure 6(d)). During the process, the plasticized material rotates counterclockwise due to the tool rotation and moves forward. This leads to the formation of layer-by-layer onion rings illustrated in Figures 6(a) - 6(d). In addition, the threaded pin transfers the material from the advancing side to the retreating side layer by layer [36]. Throughout this procedure material contain expresses the constituents of layers in the material without varying the structure of the layers [34]. The tool continuously moves forward pushing this whole layered spherical structure towards weld forward direction and forms an onion ring structure. 


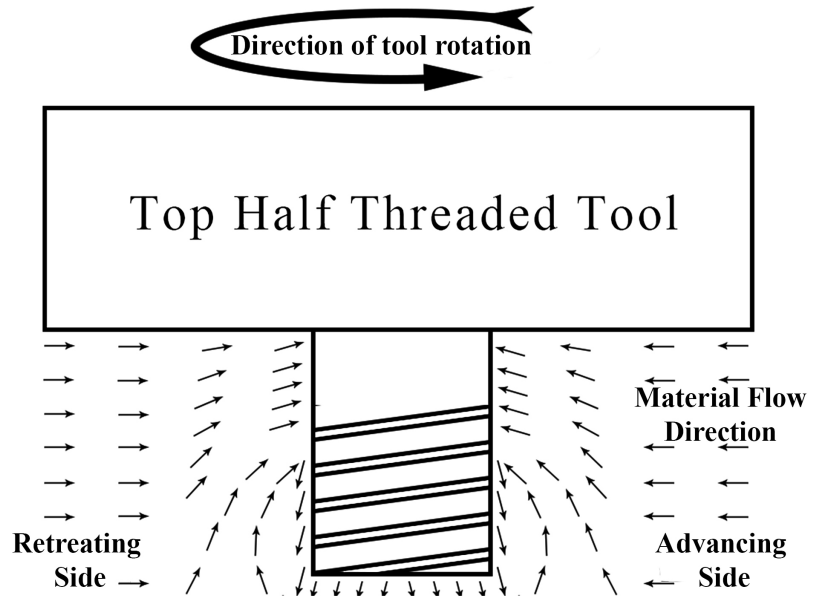

Figure 3 Material Flow direction when tool with top half threaded pin is used.

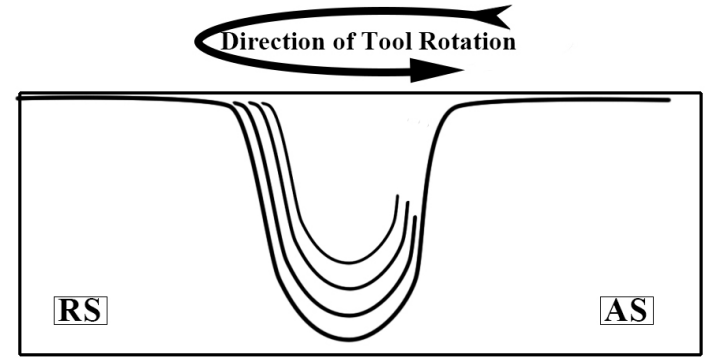

(a)

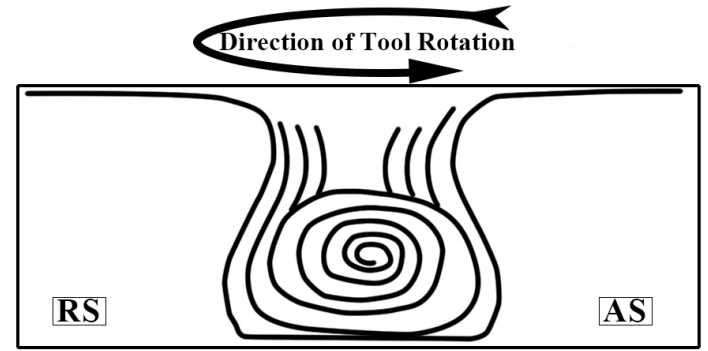

(c)

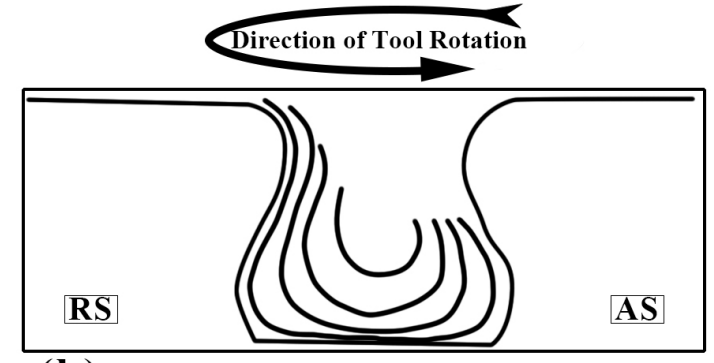

(b)

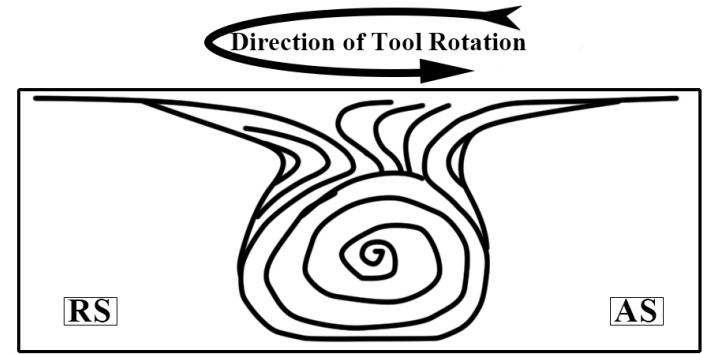

(d)

Figure 4 Material flow patterns at various steps (a) flowing of plasticized material in downward direction (b) plasticized material reached to bottom and then flowing in upward direction (c) formation for onion ring structure with high flow lines (d) creation of low flow lines near shoulder region of the weld.

\section{Hardness testing}

Micro-hardness testing is done using shimadzu microhardness tester using $1 \mathrm{Kgf}$ load for $10 \mathrm{~s}$ at 1 $\mathrm{mm}$ interval. Hardness profile of the weld cross-section is depicted in Figure 7. The peak hardness at the center is $135 \mathrm{Hv}$ and remain the same up to $4 \mathrm{~mm}$ in both advancing and retreating sides. This 8 $\mathrm{mm}$ region contains the very fine grain structure of the nugget zone. M Hakamada et.al. explained smaller grain size results in higher hardness, which is observable in present results [37]. After this high hardness region, hardness decreases in both sides up to $20 \mathrm{~mm}$. This fall in hardness is due to the TMAZ followed by HAZ where the grain size gradually increases. The lowest value of the hardness is $97 \mathrm{Hv}$ after that the hardness value starts to increase and reaches to the hardness of the base material. The high hardness of the base material is due to the precipitation hardening of aluminum alloys AA7075 and AA2024. The hardness value that has been changed due to the welding process is up to 40 
$\mathrm{mm}$ in both sides, this is the area till which the grains are influenced by the heat produced throughout welding. The ' $\mathrm{W}$ ' shape microhardness profile observed in Figure 7 is common for these aluminum alloys welded by FSW [38-41].

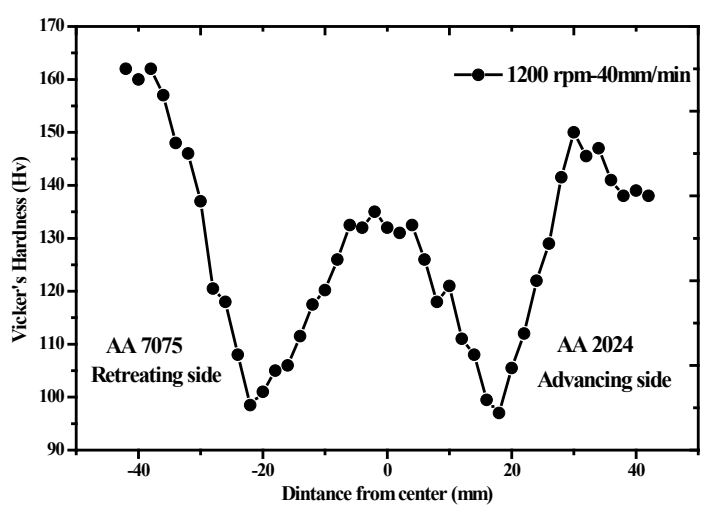

Figure 5 Hardness plot for welded cross section.

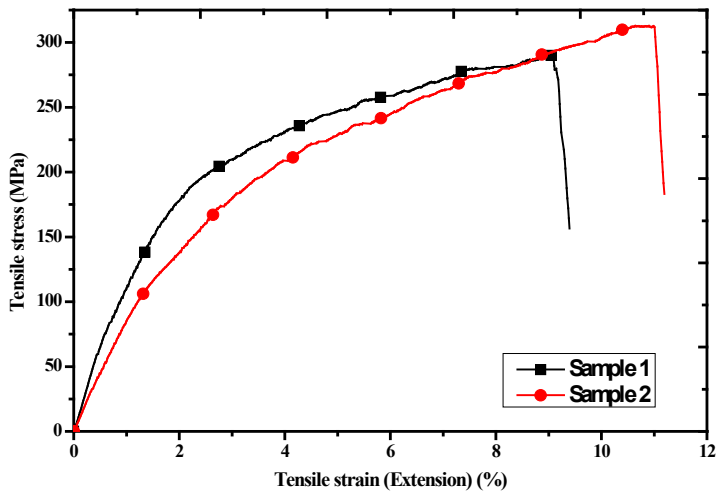

Figure 6 stress strain curve for welded samples.

\section{Tensile testing}

For tensile testing 2 specimens were prepared according to ASTM E8 standards. The samples were prepared using wire cut EDM machine. The tested samples were fractured from the interface of high flow onion ring structure and low flow region. High flow and low flow regions will be discussed in fractography section. In earlier experiments when a cylindrical pin tool was used, welded samples had micro sized void defects at the root which reduced the weld strength [24]. The top half threaded pin tool avoided those welding defects and increase the weld strength. The stress-strain curve for the welded sample is shown in Figure 8. The maximum tensile strength achieved using the new tool is $312.7 \mathrm{MPa}$, equivalent to the joint efficiency of 66.5 percent. A brief comparison of welding technique and welding parameters is given in Table 2 for the welding of AA2024 and AA7075. The present result is comparable with tensile strength achieved in literature.

Table 2 comparison of various welding technique and welding parameters used to weld AA2024 and AA7075 alloys in literature.

\begin{tabular}{|c|c|c|c|c|}
\hline No. & Base Materials & $\begin{array}{l}\text { Welding Technique and Welding } \\
\text { Parameter }\end{array}$ & $\begin{array}{l}\text { Ultimate Tensile } \\
\text { Strength (MPa) }\end{array}$ & Reference \\
\hline 01 & $\begin{array}{l}\text { AA } 2024 \text { T3 and } \\
\text { AA } 7075 \text { T6 }\end{array}$ & TIG twine electrode arc welding process & 288.35 & {$[42]$} \\
\hline 02 & $\begin{array}{l}\text { AA } 2024 \text { T6 and } \\
\text { AA } 7075 \text { T6 }\end{array}$ & $\begin{array}{l}\text { FSW with cylindrical tool pin at }(600 \mathrm{rpm} \text {, } \\
30 \mathrm{~mm} / \mathrm{min} \text { travers speed })\end{array}$ & 160 & [43] \\
\hline 03 & $\begin{array}{lcc}\text { AA } & 2024 & \text { T351 } \\
\text { and } & \text { AA } & 7075 \\
\text { T651 } & & \end{array}$ & $\begin{array}{l}\text { FSW with threaded cylindrical tool pin at } \\
\text { ( } 780 \mathrm{rpm}, 20 \mathrm{~mm} / \mathrm{min} \text { travers speed) }\end{array}$ & 276.3 & {$[24]$} \\
\hline 04 & $\begin{array}{lcr}\text { AA } & 2024 & \text { T351 } \\
\text { and } & \text { AA } & 7075 \\
\text { T651 } & & \end{array}$ & $\begin{array}{l}\text { FSW with top half threaded cylindrical } \\
\text { tool pin at }(1,200 \mathrm{rpm}, 40 \mathrm{~mm} / \mathrm{min} \text { travers } \\
\text { speed) }\end{array}$ & 312.7 & $\begin{array}{l}\text { Present } \\
\text { work }\end{array}$ \\
\hline
\end{tabular}

\section{Fractographic analysis}

The fractographic study is carried out using ZEISS EVO 18 Scanning Electron Microscope. Figure 9 has SEM images of fractured surface showing the fracture line and the difference in low flow region and high flow region. A lower magnification images shows how the fracture has 2 separate regions and the texture on both the region is completely different (Figure 9(a)). The low flow region has very rough and very uneven surface which is created by slow moving plasticized material. However, the surface of high flow region has clean and smoother texture when compared to the low 
flow region. This region has finer and uniform grains due to the fast movement of the plasticized material. Theses flow region are created via 2 different parts of the tool pin: First without threaded pin area and second threaded pin area. The fracture line between the upper and lower flow region states that the fracture may have been started from the interface of the upper and lower flow region shown in Figures 9(b) and 9(c).

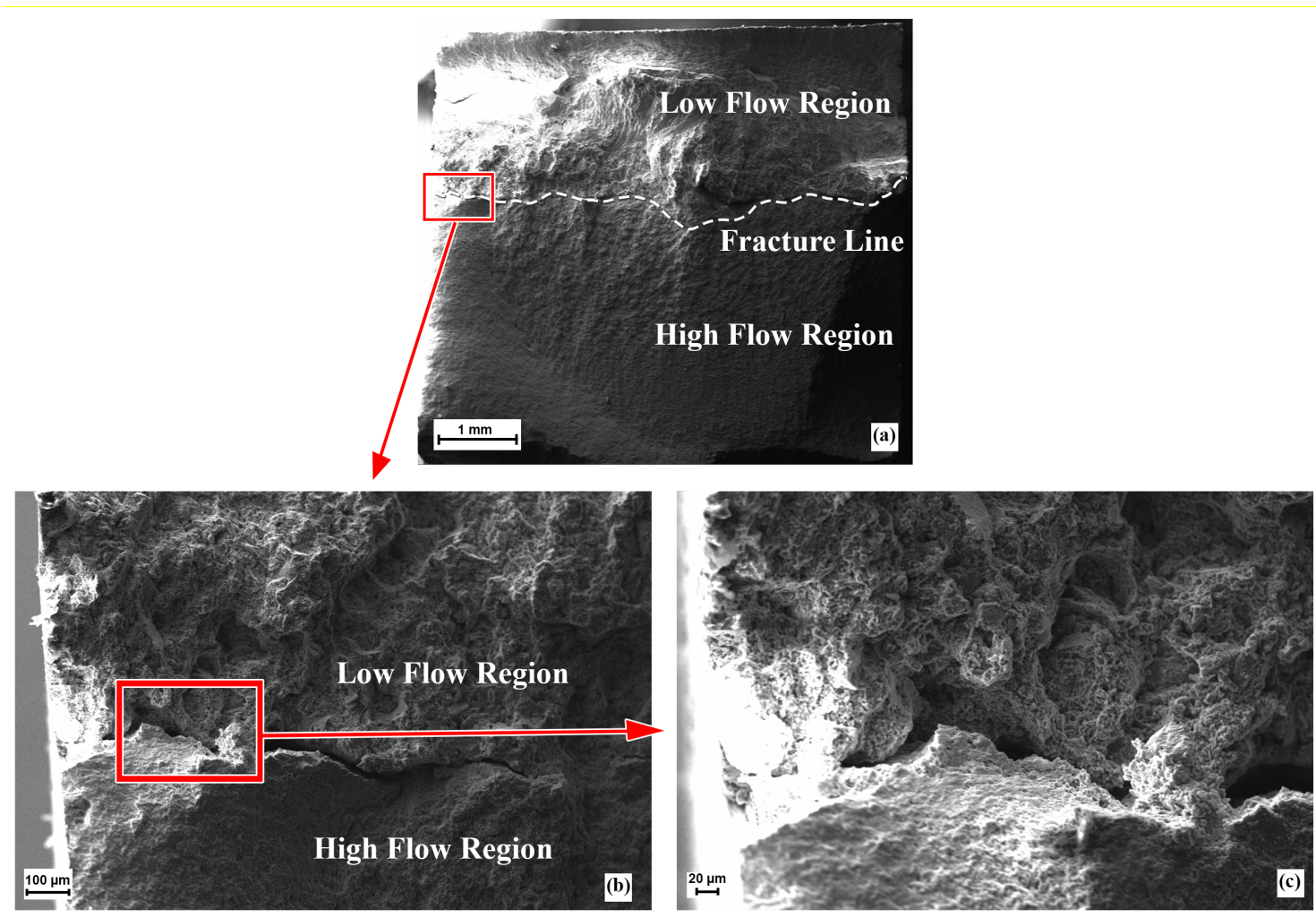

Figure 7 SEM images of Fracture surface (a) 34X magnification image showing fracture line between low flow region and high flow region (b) 200X magnification image showing micro crack (c) 500X magnification image.

Other part of the fractured sample has been analyzed for the high magnification fractography and EDX analysis shown in Figure 10. The fractography depicts the presence of prominent regions of ductile fracture. The ductile fracture is evident by of dimples [44]. Figure 10(b) is a low magnification image of sample and Figures 10(a) and 10(c) are magnified image of upper and central region. Furthermore Figures 10(d) and 10(e) are very high magnification images of upper and central regions. The top area shows ductile fracture with no precipitates shown in Figures 10(a) and 10(d). The center and bottom region that has been under influence of threaded pin has ductile fracture with precipitates presented shown in Figure 10(e). Precipitate at location 1 has atomic weight percentage of $\mathrm{Al}-21.98 \%$ and $\mathrm{Cu}-$ $77.20 \%$, hence the probable compound could be $\mathrm{AlCu}_{4}$. Precipitate at location 2 has atomic weight percentage of $\mathrm{Al} 53.78 \%, \mathrm{Cu} 22.52 \%$, and $\mathrm{Mg}$ - $23.69 \%$, hence the probable compound could be $\mathrm{Al}_{2} \mathrm{CuMg}$. 


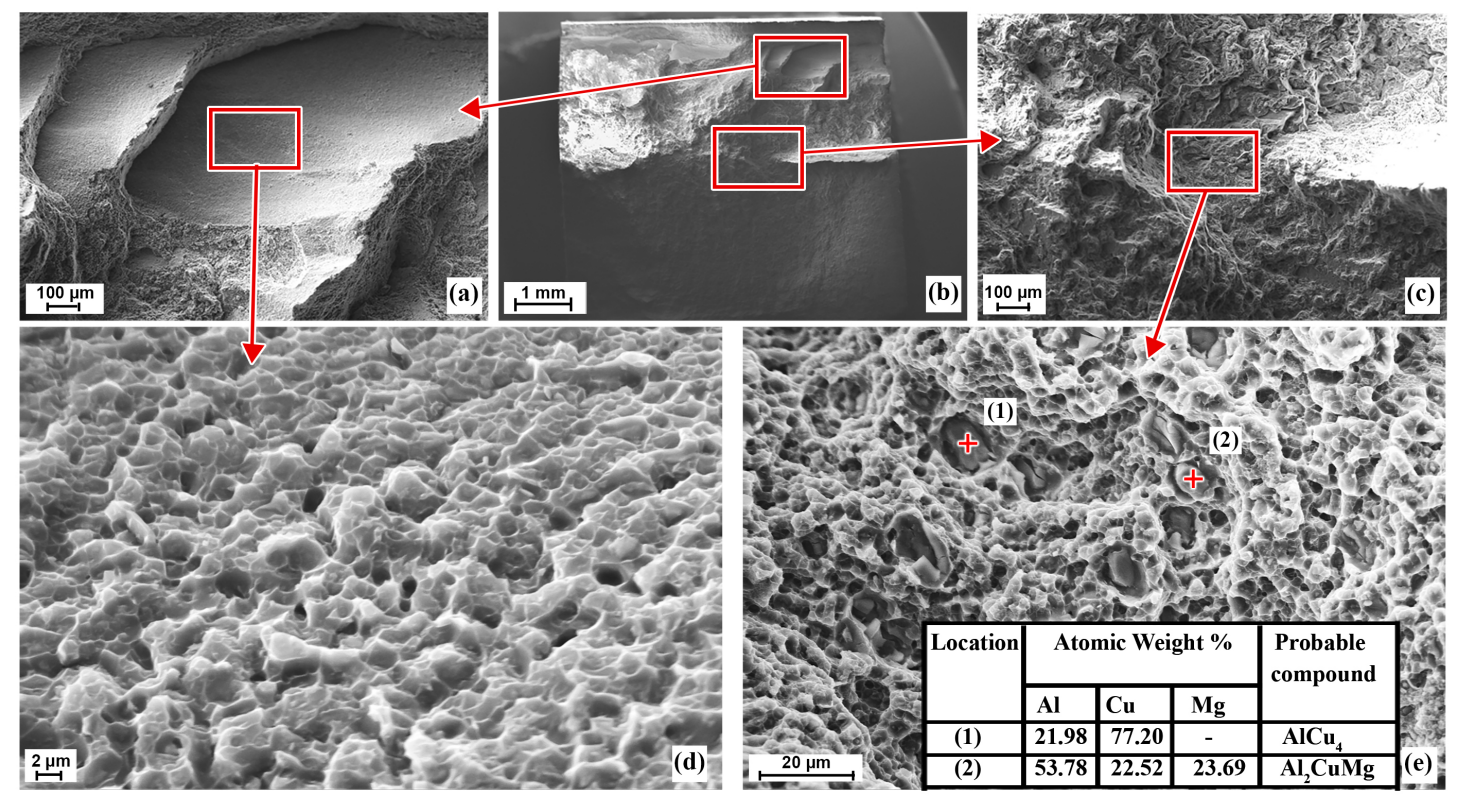

Figure 8 SEM images of Fracture Surface and EDX; (a) magnified view of upper region of fractured surface (b) low magnification fractography (c) magnified view of central region of fractured surface (d) dimples visible at higher magnification (e) precipitates present at the central region and its EDX results.

\section{Conclusions}

$6 \mathrm{~mm}$ thick AA 2024 and AA 7075 have been joined successfully by friction stir welding technique using a top half threaded pin tool. The macrostructural investigation has been revealed the material flow in the process using this tool. The threads present on the tool pin pushed the soft material downwards hence avoiding voids that may form at the root of the weld. The onion ring structure formation has been observed at the central and bottom regions. The tool pin is responsible for creating separate region at weld line: Low flow region at top and high flow region at central areas. The fractographic investigation revealed the type of failure is ductile and the presence of precipitates in fracture region of the nugget zone. The fracture started from the interface of low flow region and high flow region. The maximum tensile strength obtain is $312.7 \mathrm{MPa}$ or $66.5 \%$ joint efficiency using tool RPM 1200 and traverse speed $40 \mathrm{~mm} / \mathrm{min}$.

\section{References}

[1] IJ Polmear. Light alloys: Metallurgy of the light metals. $3^{\text {rd }}$ eds. Butterworth-Heinemann, Oxford, 1995, p. 231-2.

[2] X Meng,Y Huang, J Cao, J Shen and JF dos Santos. Recent progress on control strategies for inherent issues in friction stir welding. Prog. Mater. Sci. 2021; 115, 100706.

[3] C Zhang, G Huang, Y Cao, Q Li, Y Zhu, X Huang and Q Liu. Investigation on microstructure and localized corrosion behavior in the stir zone of dissimilar friction-stir-welded AA2024/7075 joint. $J$. Mater. Sci. 2020; 55, 15005-32.

[4] IN Fridlyander, VG Sister, OE Grushko, VV Berstenev, LM Sheveleva and LA Ivanova. Aluminum alloys: Promising materials in the automotive industry. Met. Sci. Heat Treat. 2002; 44, 365-70.

[5] S Tan, F Zheng, J Chen, J Han, Y Wu and L Peng. Effects of process parameters on microstructure and mechanical properties of friction stir lap linear welded 6061 aluminum alloy to NZ30K magnesium alloy. J. Magnes. Alloy. 2017; 5, 56-63.

[6] $\mathrm{N}$ Thakur and H Lal. Experimental comparison of tig and friction stir welding processes for aluminium 6063-T6. Int. J. Emerg. Technol. 2015; 6, 189-94.

[7] Y Chen, H Ding, JZ Li, JW Zhao, MJ Fu and XH Li. Effect of welding heat input and post-welded heat treatment on hardness of stir zone for friction stir-welded 2024-T3 aluminum alloy. Trans. Nonferrous Met. Soc. China 2015; 25, 2524-32.

[8] H Das, D Chakraborty and TK Pal. High-cycle fatigue behavior of friction stir butt welded 6061 
aluminium alloy. Trans. Nonferrous Met. Soc. China 2014; 24, 648-56.

[9] RS Mishra and ZY Ma. Friction stir welding and processing. Mater. Sci. Eng. R 2005; 50, 1-78.

[10] R Nandan, T DebRoy and HKDH Bhadeshia. Recent advances in friction-stir welding - Process, weldment structure and properties. Prog. Mater. Sci. 2008; 53, 980-1023.

[11] U Singarapu, K Adepu and SR Arumalle. Influence of tool material and rotational speed on mechanical properties of friction stir welded AZ31B magnesium alloy. J. Magnes. Alloy. 2015; 3, 335-44.

[12] MA Sutton, B Yang, AP Reynolds and R Taylor. Microstructural studies of friction stir welds in 2024-T3 alimunum. Mater. Sci. Eng. A 2002; 323, 160-6.

[13] K Subrahmanian, KK Ramachandran and R Vamadevan. Effect of tool axis offset and relative position of materials on the performance of dissimilar friction stir welded aluminium alloy joints-an overview. IOP Conf. Ser. Mater. Sci. Eng. 2021; 1114, 012066.

[14] KS Arora, S Pandey, M Schaper and R Kumar. Microstructure evolution during friction stir welding of aluminum alloy AA2219. J. Mater. Sci. Technol. 2010; 26, 747-53.

[15] W Thomas, ED Nicholas and JC Needham, MG Murch, P Templesmith and CJ Dawes. Great britain patent application No. 9125978.8. The Welding Institute, Cambridge, 1991.

[16] A Arora, A De and T Debroy. Toward optimum friction stir welding tool shoulder diameter. Scr. Mater. 2011; 64, 9-12.

[17] NB Borkar and SS Deshmukh. Qualitative and quantitative analysis of friction stir welding of 6111T4 alloy joint with preheating. Int. J. Mech. Prod. Eng. Res. Dev. 2020; 10, 115-26.

[18] RS Mishra and MW Mahoney. Friction Stir Welding and Processing. ASM International, Ohio, 2007, p. 368.

[19] P Hema, SM Gangadhar and K Ravindranath. Optimization of process parameters for friction stir welding of aluminium alloy 6061 using ANOVA. Int. J. Mech. Prod. Eng. Res. Dev. 2012; 2, 36-42.

[20] GK Padhy,CS Wu and S Gao. Auxiliary energy assisted friction stir welding: Status review. Sci. Technol. Weld. Join. 2015; 20, 631-49.

[21] M Liang, H Zhang, L Zhang, P Xue, D Ni, W Wang, Z Ma, H Ye and Z Yang. Evolution of quasicrystals and long-period stacking ordered structures during severe plastic deformation and mixing of dissimilar Mg alloys upon friction stir welding. Acta Metall Sin-Engl. 2021; 34, 12-24.

[22] S Senthilkumar, M Boopathi, TC Kanish and A Srivani. Fuzzy logic model for combined monitoring of weld strength and nugget hardness of friction stir weld. Walailak J. Sci. Technol. 2017; 14, 377-88.

[23] C Elanchezhian, B Vijaya Ramnath, P Venkatesan, S Sathish, T Vignesh, R V. Siddharth, B Vinay and $\mathrm{K}$ Gopinath. Parameter optimization of friction stir welding of AA8011-6062 using mathematical method. Procedia Eng. 2014; 97, 775-82.

[24] PN Banjare and MK Manoj. Effect of tool RPM and tool travers speed on mechanical properties of friction stir welded joints of dissimilar aluminium alloys. Int. J. Mech. Prod. Eng. Res. Dev. 2020; 10, 215-22.

[25] PN Banjare, V Gadpale and MK Manoj. Friction stir spot welding of commercial aluminum strip using a drill press. MATS J. Eng. Appl. Sci. 2018; 3. 86-91.

[26] SK Dewangan, MK Tripathi and MK Manoj. Effect of welding speeds on microstructure and mechanical properties of dissimilar friction stir welding of AA7075 and AA5083 alloy. Mater. Today Proc. 2020; 27, 2713-17.

[27] E Hoyos, Y Montoya, RF Serrano and G González-Doncel. Approach to plastic deformation and strain rate in FSW process. Weld. World 2021; 65, 1-3.

[28] P Cavaliere, R Nobile, FW Panella and A Squillace. Mechanical and microstructural behaviour of 2024-7075 aluminium alloy sheets joined by friction stir welding. Int. J. Mach. Tools Manuf. 2006; 46, 588-94.

[29] R Seetharaman, V Ravisankar and V Balasubramanian. Corrosion performance of friction stir welded AA2024 aluminium alloy under salt fog conditions. Trans. Nonferrous Met. Soc. China 2015; 25, 1427-38.

[30] Z Hu, S Yuan, X Wang, G Liu and Y Huang. Effect of post-weld heat treatment on the microstructure and plastic deformation behavior of friction stir welded 2024. Mater. Des. 2011; 32, 5055-60.

[31] N Manikandan, JS Binoj, PC Krishnamachary, P Thejasree and DA Kirubakaran. Predictive models for wire spark erosion machining of AA 7075 Alloy using multiple regression analysis. In: A Arockiarajan, M Duraiselvam and R Raju (Eds.). Advances in industrial automation and smart manufacturing. Springer Publishing, New York, 2021, p. 429-38.

[32] PN Banjare, P Sahlot and A Arora. An assisted heating tool design for FSW of thermoplastics. $J$. 
Mater. Process. Technol. 2017; 239, 83-91.

[33] K Elangovan and V Balasubramanian. Influences of pin profile and rotational speed of the tool on the formation of friction stir processing zone in AA2219 aluminium alloy. Mater. Sci. Eng. A. 2007; 459, 7-18.

[34] K Kumar and S V. Kailas. The role of friction stir welding tool on material flow and weld formation. Mater. Sci. Eng. A 2008; 485, 367-74.

[35] KJ Quintana and JLL Silveira. Effects of threaded pin profile on torque, power, and energy by modeling and experimental analysis. Int. J. Adv. Manuf. Technol. 2021; 114, 2739-51.

[36] AK Singh, P Sahlot, M Paliwal and A Arora. Heat transfer modeling of dissimilar FSW of Al 6061 / AZ31 using experimentally measured thermo-physical properties. Int. J. Adv. Manuf. Technol. 2019; 105, 771-83.

[37] M Hakamada, Y Nakamoto, H Matsumoto, H Iwasaki, Y Chen, H Kusuda and M Mabuchi. Relationship between hardness and grain size in electrodeposited copper films. Mater. Sci. Eng. A. 2007; 457, 120-6.

[38] I Radisavljevic, A Zivkovic, N Radovic and V Grabulov. Influence of FSW parameters on formation quality and mechanical properties of Al 2024-T351 butt welded joints. Trans. Nonferrous Met. Soc. 2013; 23, 3525-39.

[39] M Milčić, T Vuherer, I Radisavljević, D Milčić and J Kramberger. The influence of process parameters on the mechanical properties of friction-stir-welded joints of $2024 \mathrm{~T} 351$ aluminum alloys. Mater. Technol. 2019; 53, 771-76.

[40] A Mehri, A Abdollah-zadeh, N Habibi, M Hajian and JT Wang. The effects of rotational speed on microstructure and mechanical properties of friction stir-welded 7075-T6 thin sheet. J. Mater. Eng. Perform. 2020; 29, 2316-23.

[41] Y Chen, H Li, X Wang, H Ding and F Zhang. A comparative investigation on conventional and stationary shoulder friction stir welding of Al-7075 butt-lap structure. Metals (Basel). 2019; 9, 1264.

[42] L Kaba, L Djeghlal, O Seddik and S Kahla. Dissimilar welding of aluminum alloys 2024 T3 and 7075 T6 by TIG process with double tungsten electrodes. Int. J. Adv. Manuf. Technol. 2021. https://doi.org/10.1007/s00170-021-07888-5

[43] D Muruganandam, D Raguraman and LA Kumaraswamidhas. Effect of post-welding heat treatment on mechanical properties of butt FSW joints in high strength aluminium alloys. Indian J. Eng. Mater. Sci. 2015; 22, 381-8.

[44] SM Bayazid, H Farhangi, H Asgharzadeh, L Radan, A Ghahramani and A Mirhaji. Effect of cyclic solution treatment on microstructure and mechanical properties of friction stir welded $7075 \mathrm{Al}$ alloy. Mater. Sci. Eng. A 2016; 649, 293-300. 